\title{
Acciones colectivas en la recuperación de espacios verdes públicos: Caso Quebrada Ortega, Quitumbe, Quito-Ecuador
}

\author{
Collective actions in the recovery of public green spaces: Ortega \\ Ravine case, Quitumbe, Quito-Ecuador
}

\author{
María Daniela Zumárraga Salgado, ${ }^{1}$ Teresa Elena Pascual Wong ${ }^{2}$ y Mauricio Javier \\ Unda Padilla ${ }^{3}$
}

Fecha de recepción: 31-01-2021 - Fecha de aceptación: 30-05-2021

Hábitat y Sociedad (ISSN 2173-125X), n. ${ }^{\circ}$ 14, noviembre de 2021, pp. 51-70.

https://doi.org/10.12795/HabitatySociedad.2021.i14.04

\section{Summary}

Green spaces are protagonists in the new way of conceiving public space, where the collective actions undertaken by social organizations use natural benefits as a source of unlimited resources that improve their quality of life. In this context, public green spaces are in a favorable setting for the development of local activities. However, in the South of Quito, the logic of the State is opposed to the recovery of green areas as triggers of urban life, prioritizing the construction of massive houses and facilities before the recovery of streams and forests that are characteristic elements of the topography from the city. Here the categories of collective actions undertaken by the Alianza Solidaria Housing Cooperative in the recovery of Quebrada Ortega were analyzed and determined. Interviews, photographic archives, semiotic analysis and surveys were the techniques used to feed a mixed analysis methodology. As a result, we find that community participation and self-management are decisive collective actions in the appropriation of public spaces. Finally, the role of women becomes an essential element for executing the processes to improve the quality of life of the community.

\section{Key words}

Collective actions; Public spaces; Social management; participation; Recovery of streams; Self-management and women

\section{Resumen}

Los espacios verdes son protagonistas en la nueva forma de concebir el espacio público, donde las acciones colectivas emprendidas por las organizaciones sociales utilizan los beneficios naturales como una fuente de recursos ilimitados, que les permiten mejorar su calidad de vida. En este contexto, los espacios verdes públicos se convierten en el escenario propicio para el desarrollo de actividades locales. No obstante, en el Sur de Quito, la lógica del Estado se contrapone a la recuperación de áreas verdes como elementos detonantes de vida urbana, priorizando la construcción de viviendas masivas y equipamientos ante la recuperación de quebradas y bosques, que son elementos característicos de la topografía de la ciudad. Aquí se analizó y determinó las categorías de acciones colectivas emprendidas por la Cooperativa de Vivienda Alianza Solidaria en la recuperación de la Quebrada Ortega. Entrevistas, archivos fotográficos, análisis semióticos y encuestas fueron las técnicas usadas para alimentar una metodología de análisis mixto. Como resultado encontramos que la participación comunitaria y la autogestión son acciones colectivas determinantes en la apropiación de espacios públicos. Finalmente, el rol de las mujeres se convierte en un elemento indispensable para ejecutar los procesos de mejora de la calidad de vida de la comunidad.

\section{Pallabras clave}

Acciones colectivas; Espacio público; Organización social; Participación; Recuperación de quebradas; Autogestión y mujeres

\footnotetext{
1 Arquitecta y Máster en Estudios Urbanos. Docente Investigadora. Universidad Tecnológica Indoamérica. E-mail: danielazumarraga@uti.edu.ec. ORCID: https://orcid.org/0000-0003-1545-4841.

2 Arquitecta y Master en Conservación del Patrimonio. Docente Investigadora. Universidad Tecnológica Indoamérica. E-mail: teresapascual@uti.edu.ec. ORCID: https://orcid.org/0000-0002-7196-2317.

3 Arquitecto y Master en Estudios Urbanos. Docente Investigador.l Universidad Internacional del Ecuador. E-mail: maundapa@ uide.edu.ec. ORCID: https://orcid.org/0000-0003-1515-3766.
} 


\section{Introducción}

El proceso de urbanización de la Ciudad de Quito ha sido condicionado por la ejecución de varios planes de ordenamiento territorial como por ejemplo el Plan Regulador de Jones Odriozola (1942), el Plan Director de Urbanismo (1967), Plan Estructura Espacial Metropolitana (1993), donde la lógica segregadora de planificación marcó una tendencia de urbanización diferenciada para las clases elitistas y obreras de aquella época; obteniendo un territorio dividido con una zona norte que responde a la necesidad de esparcimiento y comodidad residencial, frente a una zona sur que presenta una dinámica industrial y de abastecimiento productivo (Carrión y Erazo, 2012). En este contexto, se produce una división desigual del espacio urbano donde las personas con mayor poder adquisitivo son las que tienen acceso a todos los bienes y servicios de la ciudad. Por otro lado, las personas en condiciones de pobreza buscan mecanismos alejados de la ciudad formal para acceder al suelo, localizándose en sectores periféricos (cerca de montañas y quebradas) para empezar a construir su hábitat.

Históricamente el crecimiento demográfico ejerce una fuerte presión sobre los accidentes geográficos de la ciudad (lagos, montañas, valles, taludes, quebradas) para convertirlos en rellenos que contengan zonas residenciales sin tomar en cuenta su función ambiental en el territorio, como por ejemplo las quebradas que regulan los flujos de agua a toda la ciudad.

En el caso concreto del Sur de Quito, en el año 1999 se crea el Plan Especial Ciudad Quitumbe orientado a la consolidación de zonas residenciales, comerciales, administrativas y espacio público (Carrión y Erazo, 2012). En este plan las quebradas serían los espacios verdes públicos que organicen la trama de este sector, no obstante, el mercado inmobiliario tuvo mayor protagonismo ya que se priorizó la construcción de aproximadamente 20000 viviendas masivas cada una de ellas con diferentes tipologías comprendidas entre 60 y 80 metros cuadrados y con un costo aproximado de 50000 a 70000 dólares. También se construyeron centros comerciales como el Quicentro Shopping del Sur, centros recreativos privados como Fundeporte y el Parque las Cuadras, el Terminal de Transporte interprovincial Quitumbe y edificios gubernamentales como la Plataforma Social. Esto consolidó un centro de poder político y financiero que beneficia a las personas con mayores ingresos económicos y fortalece las grandes cadenas de mercado (Bermúdez et al., 2016). Espín (2012) y Mena (2016) explican este fenómeno a partir de la influencia del pensamiento colonial en las formas jerárquicas de organización espacial, marcadas por la implantación de proyectos inmobiliarios como reguladores del tejido urbano y los procesos históricos segregadores, que se reproducen en el territorio con la planificación urbana al incorporar zonas temáticas en la ciudad de acuerdo con las características económicas de la población.

En este contexto, aproximadamente mil familias del sector de Quitumbe, ubicado en el sur de Quito, cansadas de ser arrendatarias y al no tener la capacidad económica para acceder a una vivienda propia en los proyectos planificados por las autoridades, deciden organizarse y constituir una organización social bajo el respaldo jurídico de la Ley de Cooperativas del Ecuador, que les permita construir con sus propios recursos un complejo de viviendas de interés social para mejorar su calidad de vida (COOVIAS, 2012). Es así cómo se constituye en los años noventa la Cooperativa de Vivienda Alianza Solidaria (Figura 1). 

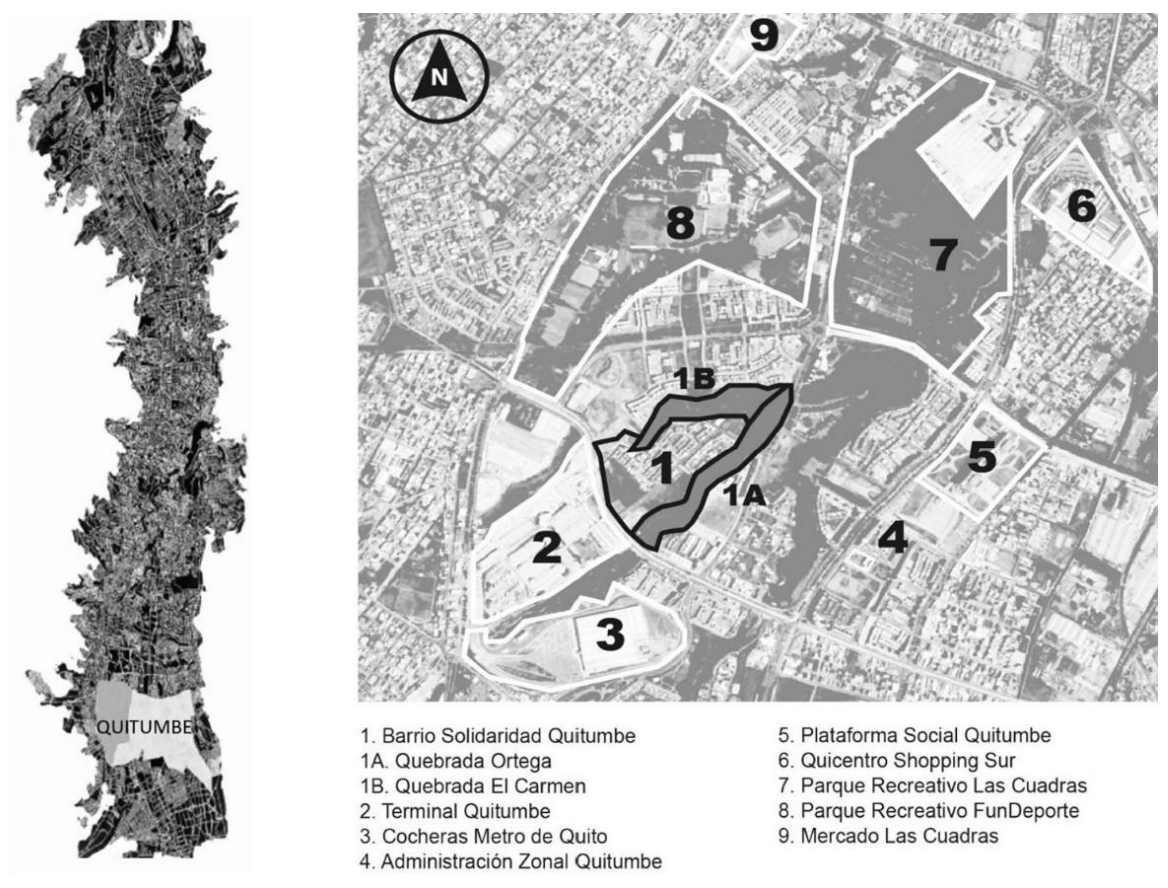

Como primera acción, la cooperativa adquiere con los ahorros de sus miembros seis hectáreas de suelo al Municipio de Quito, con la intención de dotarlo de servicios básicos y obras de urbanización. Sin embargo, al reconocer el lugar los miembros de la cooperativa quedaron asombrados y decepcionados al ver que la tierra que adquirieron estaba rodeada por dos quebradas (Ortega y El Carmen) que no estaban registradas en los planos entregados por las autoridades. En ese momento, los miembros de la cooperativa entendieron que el Estado da muchas facilidades de acceso al suelo a las grandes empresas inmobiliarias, mientras que a las organizaciones sociales les asignan terrenos residuales sin muchas probabilidades de urbanización (COOVIAS, 2012). Finalmente, a pesar de que algunos miembros de la cooperativa desertaron del proyecto por no aceptar la idea de vivir al lado de una quebrada, las personas optimistas de este objetivo decidieron que la recuperación de la quebrada es una buena alternativa para sumar un espacio verde comunal contiguo a sus viviendas que sin duda mejoraría notablemente sus condiciones de vida en contacto con la naturaleza. Después de diez años de trabajo cooperativo (mingas) se recuperaron seis kilómetros de quebrada y se construyó terrazas de siembra, senderos ecológicos, parques infantiles, puentes, planta de tratamiento de agua y la primera ciclovía de la ciudad de Quito y sobre todo un lugar de encuentro con la naturaleza donde la comunidad se siente libre de expresar sus ideas, tomar decisiones en beneficio colectivo.

En este contexto, el objetivo de esta investigación es analizar e identificar la tipología de las acciones colectivas emprendidas por la Cooperativa Alianza Solidaria, en la recuperación de la Quebrada Ortega, sector de Quitumbe, Quito.

\section{Aproximaciones Teóricas}

En América Latina, el espacio público es concebido a partir de tres posturas que emergen del proceso de urbanización excluyente e inequitativo que han experimentado las ciudades. La primera surge de la lógica de la planificación estatal, donde el espacio público es un elemento de
Figura 1: Mancha urbana de la Ciudad de Quito y ubicación del sector de Quitumbe. Fuente: Elaboración propia. 
la imagen urbana que ofrece diversas formas de uso e intercambio social a partir de su configuración espacial (Gierhake y Jardon, 2015). En este sentido, los ciudadanos están sujetos al poder público para ejercer el derecho de uso y disfrute del espacio público.

La segunda postura surge de la lógica del mercado, donde el espacio es concebido bajo la dinámica de consumo. En este escenario, las condiciones socio-económicas de la población cumplen un rol decisivo en el acceso y usufructo del mismo, lo que genera que la sociedad experimente una desnaturalización del encuentro colectivo (Harvey, 2012; Pérez, 2018).

Finalmente, la tercera postura se desarrolla a partir de la lógica de la necesidad, donde se concibe el espacio público como un escenario dinámico que se "produce, reproduce y transforma" (FernandezDroguett, 2017, p. 100) a partir de la acción colectiva emprendida por las personas excluidas y oprimidas por el sistema capitalista (Lefevre, 2020).

En este sentido, el espacio público es producto de la dinámica y características de la estructura social de las ciudades. Donde por un lado representa el poder y control de la vida urbana (a partir de las lógicas del estado y mercado) y por otro el conflicto social y la posibilidad de desafiar al sistema (lógica de la necesidad). Es así como el espacio público, concebido a partir de la necesidad social, toma protagonismo y las acciones colectivas se convierten en una herramienta para producirlo. Las acciones colectivas son entendidas como el "resultado de intenciones, recursos y límites con una orientación construida por medio de relaciones sociales dentro de un sistema de oportunidades y restricciones" (Melucci, 1999, p. 42). Lo que genera un sin número de beneficios (económicos, políticos, ambientales, sociales, ambientales, espaciales) para las personas que son parte de la organización social (Olson, 1986). En este sentido, cada miembro desempeña un rol específico que desencadena una serie de acciones colectivas que se ejecutan de acuerdo a las intenciones de cada individuo en beneficio de la organización. Como por ejemplo el papel que desempeñan los líderes generando estrategias para organizar y conservar las acciones colectivas al mismo tiempo que se encargan de sumar más miembros con intereses afines (Olson, 1986). Para Melucci (1999) esta dinámica de acción por roles se convierte en un incentivo social que produce momentos de "entusiasmo colectivo" o "gran densidad moral" donde se alinean acuerdos o ideales para llevar a cabo el proceso de acción colectiva.

En este contexto, el espacio público surge a partir del incentivo de producir un bien común donde no existan restricciones (acceso y uso) y la comunidad pueda disponer de este recurso para su beneficio de una forma libre y democrática (Guadarrama y Pichardo, 2021). Es así como las organizaciones sociales se apropian del espacio público y son capaces de participar activamente en la toma de decisiones para defender y modificar los intereses colectivos (Anduze, 2019).

Participar es, sin duda alguna, uno de los actos sociales más representativos para ejercer la ciudadanía, y el espacio público juega un papel protagónico al ser el lugar donde se desarrolla el diálogo entre los diferentes actores ya sean estos miembros del Estado o ciudadanos (Anduze, 2019). En este sentido, el espacio público trasciende su dimensión física y adquiere una dimensión simbólica que representa la lucha y el cooperativismo social. En el contexto del Ecuador, el cooperativismo se define como "una acción colectiva destinada para llevar a 
cabo obras en beneficio comunitario o de beneficio familiar, denominadas de diferentes maneras: minga, trabajo mancomunado, cambia manos" (Da Ros, 2007, p. 251). La misma que tienen el respaldo jurídico desde el año de 1937 (ley de cooperativas del Ecuador) para transformar el territorio y cubrir las necesidades de producción (agrícolas, agropecuarias, ganaderas), consumo (vivienda urbana), económicas (ahorro y crédito) y servicios (asistencia médica, construcción, educación y transporte) que tiene la comunidad.

Finalmente, este tipo de acción colectiva aporta una dimensión ambiental al espacio público a partir del uso de los beneficios naturales (materia prima para la construcción, productos alimenticios y ornamentales, calidad de aire) en la construcción del hábitat productivo. Para Priego (2011), la búsqueda del bienestar social provoca que los espacios verdes ya no sean considerados como modelos emergentes de integración urbana, sino espacios donde se incentiva la relación hombre y naturaleza. Los espacios verdes por un lado reconstruyen el grado de naturalidad social perdido en los espacios públicos tradicionales y por otro se convierten en un recurso que incentiva la autogestión de las acciones colectivas (Verdejo, 2013; Rodrigo y Astorga 2014; Ospina y Clavijo, 2020). Para Ceballos y Tovar (2010), la autogestión constituye un proceso social donde los miembros de una comunidad u organización social satisfacen automáticamente y en un tiempo más corto sus necesidades, a medida que se cuente con recursos y se tenga un objetivo fijo. De esta forma, los espacios verdes públicos se convierten en el medio y recurso que hace posible la producción social del hábitat. Esto lleva a que las organizaciones sociales de América Latina incorporen los espacios verdes como un nuevo elemento para concebir el espacio público (Colding y Barthel, 2013; Fry, 2020).

\section{Materiales y Métodos}

\section{Diseño Exploratorio Derivado}

Para identificar la tipología de las acciones colectivas emprendidas por la Cooperativa Alianza Solidaria en la recuperación de la Quebrada Ortega, la presente investigación desarrolló una aproximación mixta (cualitativa y cuantitativa) a lo largo de los años 2019 y 2020. Varios autores (Creswell, 2013; Echevarría, 2019; Grinnell y Unrau, 2005; Niglas, 2010) consideran que la aproximación mixta permite obtener una perspectiva ampliada de los fenómenos estudiados, proporcionando mayor seguridad y certeza sobre las conclusiones científicas (Todd et al., 2004).

En un primer momento, para contextualizar la relación entre la resistencia social de los habitantes del sur de Quito y el rescate de la Quebrada Ortega, se aplicó técnicas cualitativas de levantamiento de datos (Strauss y Corbin, 2002; Delgado, 2007; González-Díaz y Serrano, 2020) que incluyeron: a) entrevistas semiestructuradas aplicadas a cuatro líderes históricos de la Cooperativa Alianza Solidaria, b) análisis de bancos fotográficos del proceso de transformación de la Quebrada Ortega expuestos en el museo de sitio de la Cooperativa y, por último, c) un análisis semiótico a partir de dibujos realizados por veinte niños de la comunidad de 8-11 años, que participaron en el taller "Dibuja tu Barrio Solidaridad Quitumbe”. 
En un segundo momento y con un enfoque cuantitativo (Sautu et al., 2005; Forni y Grande, 2020), a través de una estadística descriptiva se cuantificó la influencia de distintos actores sociales en la creación de modelos de autogestión colectiva. Para esto se aplicó encuestas con preguntas cerradas a cien miembros de la Cooperativa involucrados en autogestión comunitaria, una vez que se terminó el proceso de rehabilitación de la Quebrada Ortega.

Considerando la diversidad de datos obtenidos, el análisis consiste en la elaboración de categorías a partir de un diseño exploratorio secuencial derivativo (Hernández, Fernández y Baptista, 2006). Los datos cuantitativos se analizan sobre la base de los resultados cualitativos con el objetivo de construir una muestra teórica, así como se muestra en la Cuadro 1. Para George y Bennett (2005) y Creswell (2013), este proceso genera una tipología de teorías emergentes que, vinculadas a teorías generales, se convierten en aportes significativos derivados del caso de estudio.

\section{Resultados}

El diseño exploratorio derivado arrojó cinco categorías que explican la tipología de acciones colectivas de la Cooperativa Alianza Solidaria en la Recuperación de la Quebrada Ortega: (1) La resistencia como herramienta de organización social, (2) Recuperación y Cotidianidad, (3) Participación y Valoración Ambiental, (4) Autogestión y Mujeres, (5) Estado y Cooperativa Alianza Solidaria (Cuadro 1).

\section{La resistencia como herramienta de organización social}

Tanto las entrevistas a líderes comunitarios como las encuestas a los moradores de la Asociación identifican a la "Resistencia" como el detonante que determina el nacimiento de la Cooperativa de Vivienda Alianza Solidaria en el año 1992. Llegando a ser la herramienta utilizada por la organización social para contrarrestar la exclusión histórica del sur de la ciudad. En efecto, para el imaginario colectivo, el sur de Quito es una zona informal y deshumanizada, alejada de los límites de la ciudad formal y con su propio estilo de vida. El sur de Quito es considerado como los extramuros de la ciudad, donde habitan los individuos que han renunciado a la posibilidad de ascenso social.

Sin embargo, los dirigentes de la cooperativa afirman que la comunidad del sur se caracteriza por su alegría, bulla, movimiento y trabajo, donde la interacción vecinal se convierte en un elemento esencial para el desarrollo de la vida urbana. Esto hace del espacio público el escenario propicio para tejer una red de lazos vecinales con el objetivo de subsistir. Por lo tanto, para los dirigentes de la Cooperativa Alianza solidaria la resistencia es el resultado de dos componentes importantes: a) las asambleas vecinales y b) ejercer el derecho a la ciudad. Los mismos que en interacción permanente se convierten en una herramienta para organizar el territorio.

Asimismo, la dinámica social del sur de Quito está orientada a replicar comportamientos y prácticas colectivas en todos los sectores de esta zona. Los moradores del sector afirman que el territorio es la materialización de su forma de habitar enmarcada en la lucha permanente para mejorar sus condiciones de vida, la misma que debe ser respetada por el resto de la ciudad. La producción social del hábitat es una 


\begin{tabular}{|c|c|c|c|}
\hline Actores & Técnica & Variables Cualitativo y Cuantitativo & $\begin{array}{l}\text { Categorías de Acciones } \\
\text { Colectivas }\end{array}$ \\
\hline \multirow{5}{*}{ Lideres } & \multirow{5}{*}{ Entrevista } & $\begin{array}{l}\text { Exclusión, segregación, resistencia, organización, lucha, } \\
\text { asambleas }\end{array}$ & Resistencia \\
\hline & & $\begin{array}{l}\text { Necesidades comunes, rescate, bienestar colectivo, } \\
\text { mingas, proyecto de vida, cotidianidad como espacio }\end{array}$ & $\begin{array}{l}\text { Recuperación y } \\
\text { cotidianidad }\end{array}$ \\
\hline & & $\begin{array}{l}\text { Beneficios naturales, valoración organización social, } \\
\text { participación comunitaria }\end{array}$ & $\begin{array}{l}\text { Participación y valoración } \\
\text { ambiental }\end{array}$ \\
\hline & & Autogestión, economía local, mujeres líderes & Autogestión y mujeres \\
\hline & & Participación estatal y tiempo & $\begin{array}{l}\text { Mediaciones políticas y } \\
\text { Estado }\end{array}$ \\
\hline Niños & $\begin{array}{l}\text { Análisis } \\
\text { semiótico }\end{array}$ & $\begin{array}{l}\text { Apropiación y valoración de los espacios verdes, } \\
\text { beneficios para la salud }\end{array}$ & $\begin{array}{l}\text { Participación y valoración } \\
\text { ambiental }\end{array}$ \\
\hline \multirow{8}{*}{ Moradores } & \multirow{8}{*}{$\begin{array}{l}\text { Encuesta } \\
\text { y archivos } \\
\text { fotográficos }\end{array}$} & $\begin{array}{l}\text { Considera usted qué el estado actual de la Quebrada } \\
\text { Ortega es el resultado del esfuerzo participativo y } \\
\text { organización comunitaria }\end{array}$ & Resistencia \\
\hline & & $\begin{array}{l}\text { Con el rescate de la Quebrada Ortega que aspectos han } \\
\text { mejorado para la dinámica comunal }\end{array}$ & Rescate y cotidianidad \\
\hline & & $\begin{array}{l}\text { Que beneficios han aparecido a partir del rescate de la } \\
\text { Quebrada }\end{array}$ & $\begin{array}{l}\text { Participación y valoración } \\
\text { ambiental }\end{array}$ \\
\hline & & $\begin{array}{l}\text { Como considera la gestión de su comunidad respecto al } \\
\text { manejo de la Quebrada y los otros espacios verdes del } \\
\text { sector }\end{array}$ & $\begin{array}{l}\text { Participación y valoración } \\
\text { ambiental }\end{array}$ \\
\hline & & $\begin{array}{l}\text { En cuestiones de género, quienes considera usted } \\
\text { organizan los procesos de autogestión comunitaria }\end{array}$ & Autogestión y mujeres \\
\hline & & $\begin{array}{l}\text { Estaría dispuesto a pagar un valor económico por el } \\
\text { uso de servicios o compra y productos en el restaurante } \\
\text { comunitario }\end{array}$ & Autogestión y mujeres \\
\hline & & $\begin{array}{l}\text { Quienes debe participar en la recuperación de los } \\
\text { espacios verdes públicos }\end{array}$ & Autogestión y mujeres \\
\hline & & $\begin{array}{l}\text { Considera usted que en el proceso de recuperación de la } \\
\text { quebrada existió respaldo estatal }\end{array}$ & $\begin{array}{l}\text { Mediaciones políticas y } \\
\text { Estado }\end{array}$ \\
\hline
\end{tabular}

construcción socio cultural y no de consumo. Cubrir necesidades de subsistencia, protección, identidad, libertad, acceso a la naturaleza y conservación de la familia, son el objetivo de la Cooperativa de Vivienda Alianza Solidaria. Esto genera nuevas expresiones culturales, como caminatas nocturnas, cosecha de alimentos, fiestas al aire libre, arte y graffiti, autoconstrucción de viviendas y equipamientos, las mismas que se materializan en relaciones sociales permanentes. Sin embargo, esta dinámica del sur de Quito es concebida por el resto de la ciudad como hostil y peligrosa.

Los dirigentes afirman que no es necesario el acompañamiento del Estado en estos procesos ya que la ciudadanía ejercida desde la ciudad formal solo se limita a la obediencia y destruye el derecho de transformación de la misma. En este sentido, la concepción del territorio está enfocada en la creación de espacios públicos multifuncionales donde las prácticas sociales y productivas de la comunidad creen el hábitat necesario para producir ciudad.
Cuadro 1: Categorización y diseño exploratorio derivativo. Fuente: Elaboración propia. 
Uno de los dirigentes de la Cooperativa de Vivienda Alianza Solidaria afirma que las soluciones habitacionales y estrategias de movilidad urbana no deben desconocer las ventajas que ofrece el medio ambiente. El paisaje urbano debe generar una armonía entre perfiles arquitectónicos y el medio natural, el mismo que alberga una diversidad de especies de flora y fauna que deben coexistir con el ser humano. En este sentido, la comunidad debe ejercer el derecho a la ciudad, no con el objeto de mostrarse, sino con la necesidad de transformar la ciudad para encontrar el bien común (Entrevista a Dirigente. Cooperativa de Vivienda Alianza Solidaria, 2016).

\section{Recuperación y cotidianidad}

A partir de las entrevistas a los líderes comunitarios y los resultados de las encuestas a moradores de la cooperativa se identificó al "Recuperación y cotidianidad" como una segunda categoría. En este caso, la acción colectiva de recuperación de la Quebrada Ortega fue inducida por la única posibilidad que tenían personas de escasos recursos económicos de acceder a una vivienda. Negociaciones entre autoridades y algunos líderes comunitarios del sur de Quito, terminó en la asignación de tierras residuales en la zona de Quitumbe para aproximadamente mil familias (Figura 2A). Aproximadamente quinientas familias aceptaron la propuesta de construir su vivienda y la primera idea que surgió fue rellenar las quebradas con el objetivo de tener mayor extensión de suelo para construir. Sin embargo, después de varias asambleas se tomó la decisión de recuperar la quebrada ya que era el entorno natural inmediato para la comunidad y antesala para construir sus viviendas (Entrevista a Dirigente. Cooperativa Vivienda Alianza Solidaria, 2016).
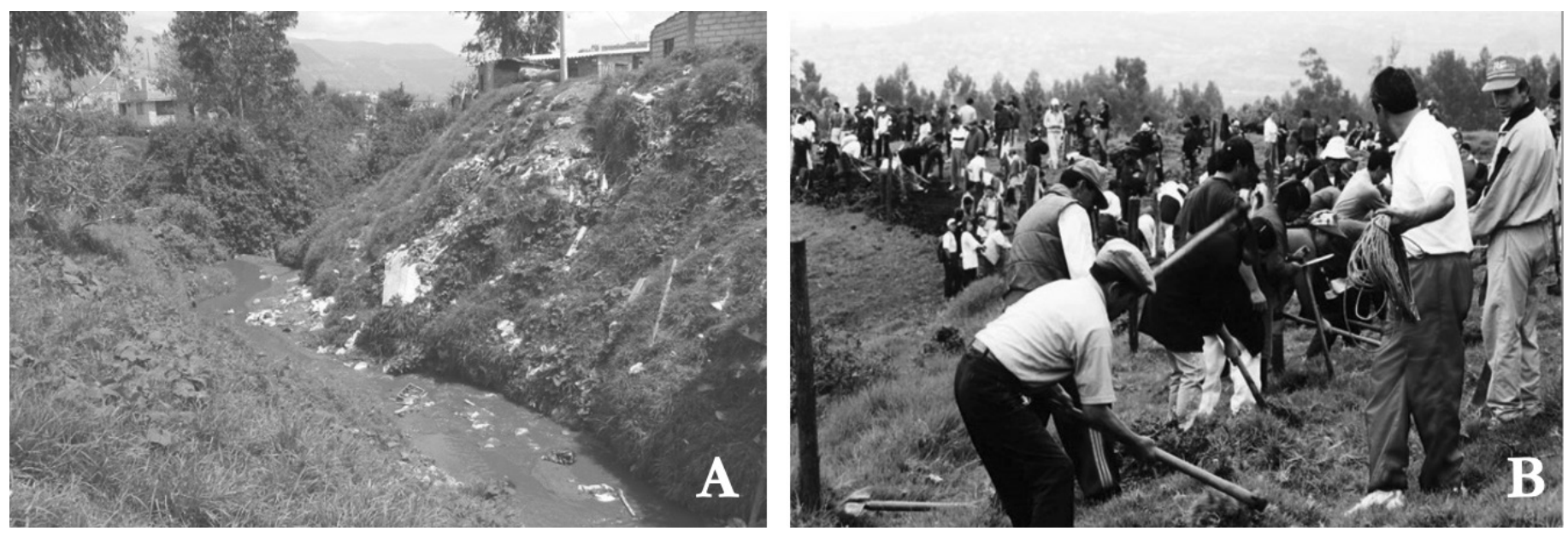

Figura 2: A) Terreno asignado por las autoridades a la Cooperativa Alianza Solidaria. Quebrada Ortega. B) Jornada Comunitaria (Mingas). Fuente: COOVIAS (2012)
Como afirman los líderes de la comunidad, este proceso se convirtió en su proyecto de vida. Largas jornadas de caminatas, limpieza, movimiento de tierras, descanso y camaradería se reprodujeron aceleradamente durante diez años consecutivos (Figura 2B). En este sentido, la minga, según el $80 \%$ de los moradores, se convirtió en la actividad cotidiana de hombres, mujeres y niños de la comunidad, que transformó el territorio (Figura 3A) y dotó a la comunidad de un espacio verde que mejora notablemente su salud y sus condiciones de vida. Los líderes afirman que el espacio público en los sectores populares se reduce a la inserción de canchas deportivas, donde no existe un lugar para la construcción cultural del barrio, sin embargo, para el $60 \%$ de moradores el 
rescate de la quebrada se convirtió en un espacio público que alberga prácticas comunitarias (Figura 3B) (Entrevista a Dirigente-Cooperativa Vivienda Alianza Solidaria, 2016).

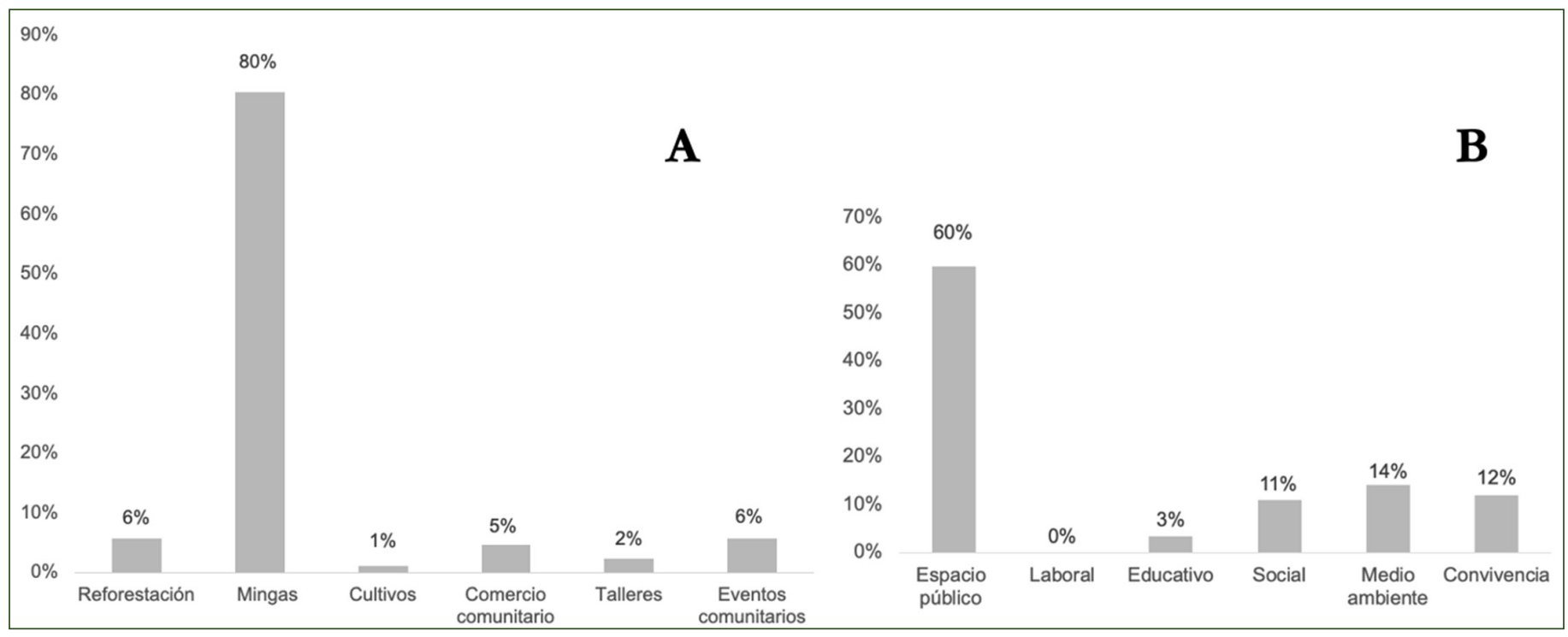

\section{Participación y Valoración ambiental}

A partir de las entrevistas a los líderes comunitarios y los resultados de las encuestas a moradores de la cooperativa se identificó la "Valoración ambiental y Participación", como una tercera categoría. Todos los moradores después de cada jornada emprendida en la recuperación de la Quebrada Ortega se reúnen en asambleas para evaluar resultados y socializar el aprendizaje adquirido. En este sentido, la concientización de las prácticas comunales permite afianzar patrones de comportamiento participativo de una organización social. Con esto se asegura la transmisión de conocimientos por varias generaciones y se convier-
Figura 3: (A) Actividades de la comunidad con respecto a la recuperación del espacio público. (B) Aspectos que mejoran en la comunidad a partir de la recuperación de la Quebrada.

Figura 4: (A) Aspectos que mejoran en la comunidad en orden de importancia. (B) Gestión de la comunidad respecto al manejo de la Quebrada. Fuente: Elaboración Propia.

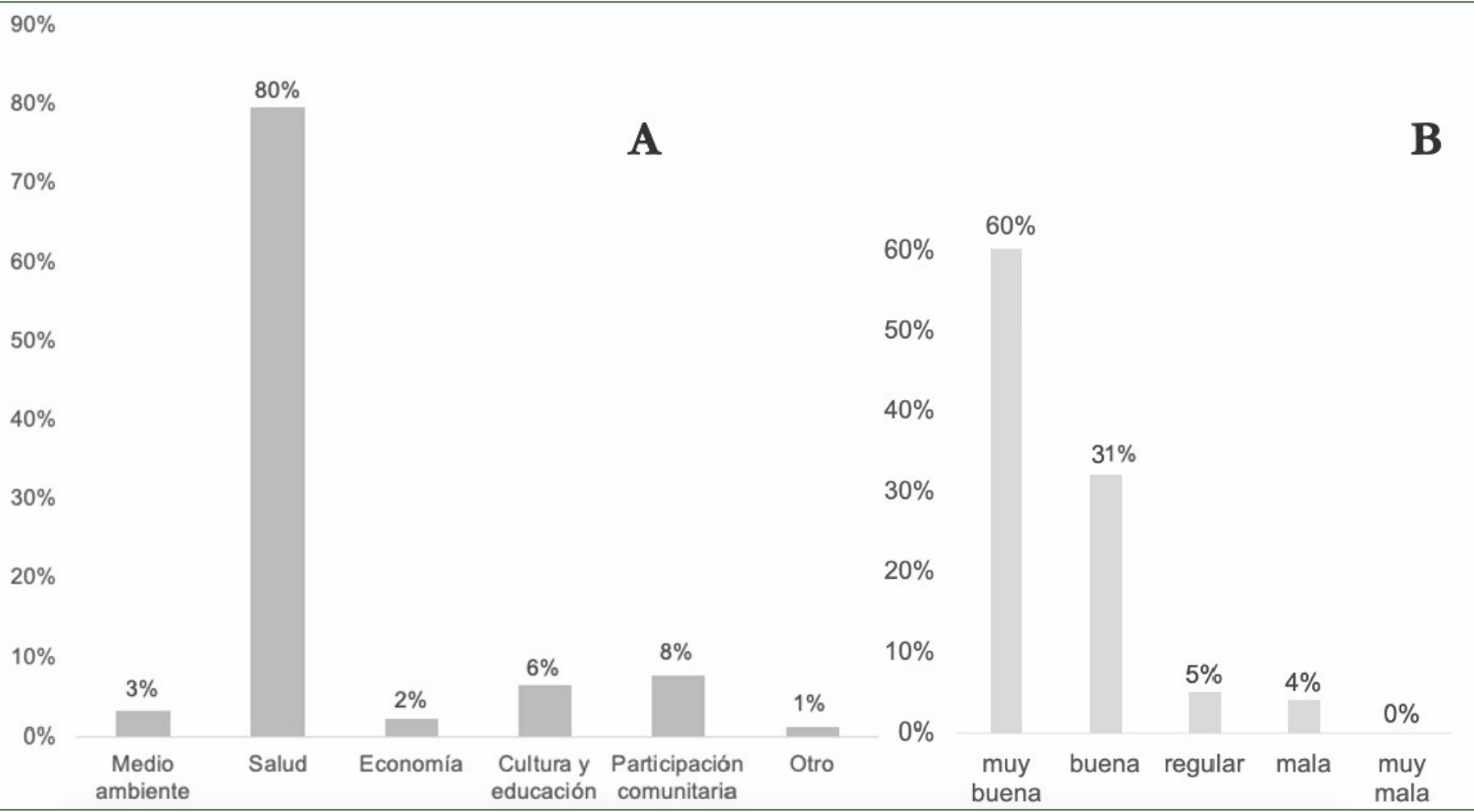


te en un valor colectivo que se reproduce fácilmente. El contacto con la naturaleza, para el $80 \%$ de los moradores de la cooperativa, mejora la salud de los habitantes y al mismo tiempo se convierte en el escenario donde se expresa cultura (Figura 4A). Por todos estos beneficios, para el 60\% de los moradores, la gestión de recuperación de la Quebrada Ortega fue entre muy buena y buena (Figura 4B), lo que accionó prácticas ambientales y de aprovechamiento de los recursos naturales como la reforestación donde los niños y niñas fueron protagonistas (Figura 5A).

Los veinte niños y niñas de la comunidad formaron parte del taller participativo "Dibuja tu Barrio Solidaridad Quitumbe", donde demostraron por medio de sus dibujos la transformación no solo de la imagen urbana del sector, sino la necesidad de incorporar la naturaleza como parte indispensable para concebir un hábitat total (Figura 5B). Esto se visualiza en los cambios de patrones de comportamiento infantil, como por ejemplo mayores niveles de satisfacción al tener contacto permanente con otros niños para recrearse y compartir actividades de reforestación.
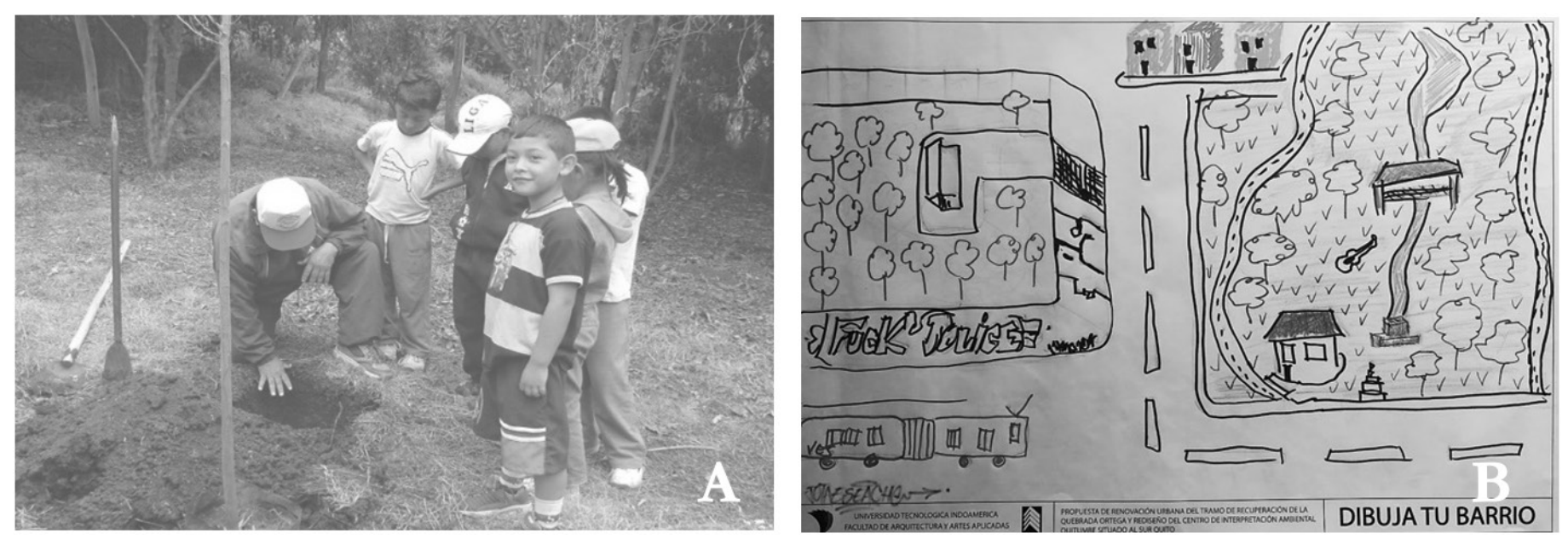

Figura 5: (A) Reforestación por niños de la Cooperativa Alianza Solidaria. (B) Análisis semióticos a partir de bocetos de los niños y niñas en el "Taller dibuja tu barrio". Fuente: COOVIAS (2012).
Del mismo modo, la comunidad afirma que los beneficios de los espacios verdes, en especial de los ejes boscosos dentro de la Quebrada Ortega, se convirtieron en una cortina natural que ayuda a controlar el smog de los autos y la contaminación sonora. El conocimiento de este tipo de beneficios naturales provocó que los miembros de la cooperativa decidieron construir sus viviendas sin darle la espalda a la quebrada (Figura 6A). Actualmente, existen numerosas especies de flora y fauna que ayudan a armonizar el entorno. Los pájaros son parte del paisaje y su canto tiene una influencia en el ánimo de los moradores. Por otro lado, la exploración del tramo de la Quebrada Ortega permitió conservar especies endémicas del sector, donde varios biólogos nacionales y extranjeros descubrieron la planta Salvia Quitensis, que en la actualidad es considerada como una de las especies de plantas patrimoniales de la ciudad de Quito. La valoración ambiental de esta cooperativa permitió que esta acción trascienda fuera de los límites del sector y la Quebrada Ortega se convierta en un espacio verde público reconocido en toda la ciudad de Quito y también en todo el Ecuador (Entrevista a DirigenteCooperativa de Vivienda Alianza Solidaria, 2016) (Figura 6B). 

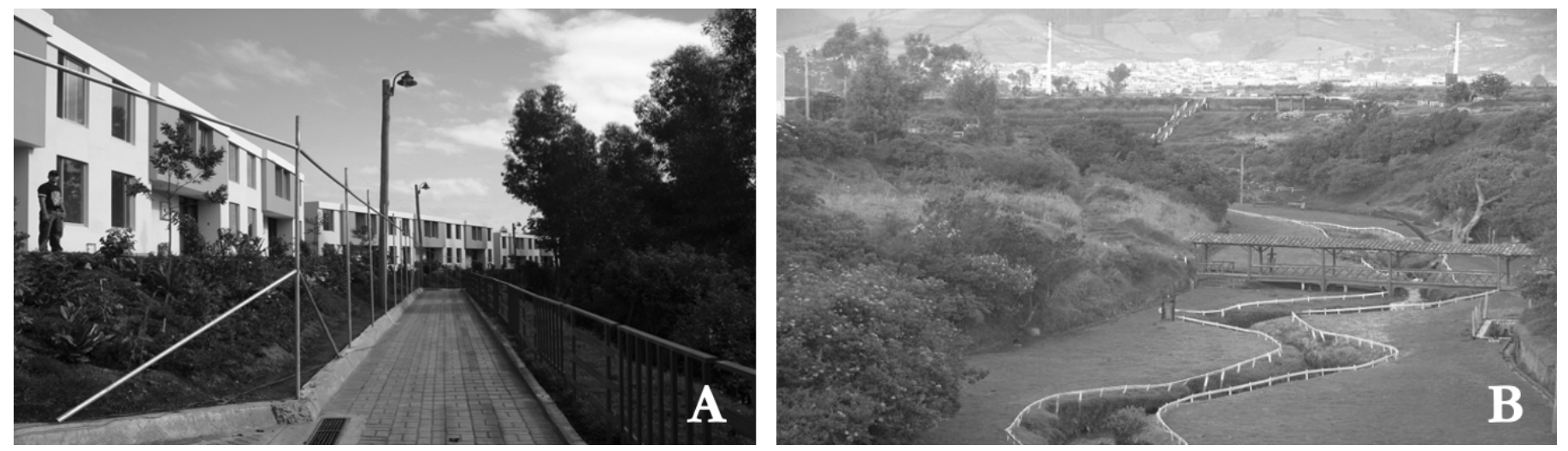

\section{Autogestión y Mujeres}

A partir de las entrevistas a los líderes comunitarios y los resultados de las encuestas a moradores de la cooperativa se identificó la "Autogestión y Mujeres", como una cuarta categoría. Para los dirigentes de la Cooperativa Alianza Solidaria, participar es asumir responsabilidades, mientras que la autogestión es proponer y buscar los recursos para desarrollar un objetivo en común. La autogestión es una decisión comunal donde se evalúa las propuestas y métodos de materialización de un objetivo, no solo desde las estrategias de los líderes, sino desde las necesidades de la organización vecinal.
Figura 6: (A) Disposición de las viviendas integrándose con la Quebrada Ortega. (B) Parque ecológico de la Quebrada Ortega. Fuente: COOVIAS (2012).

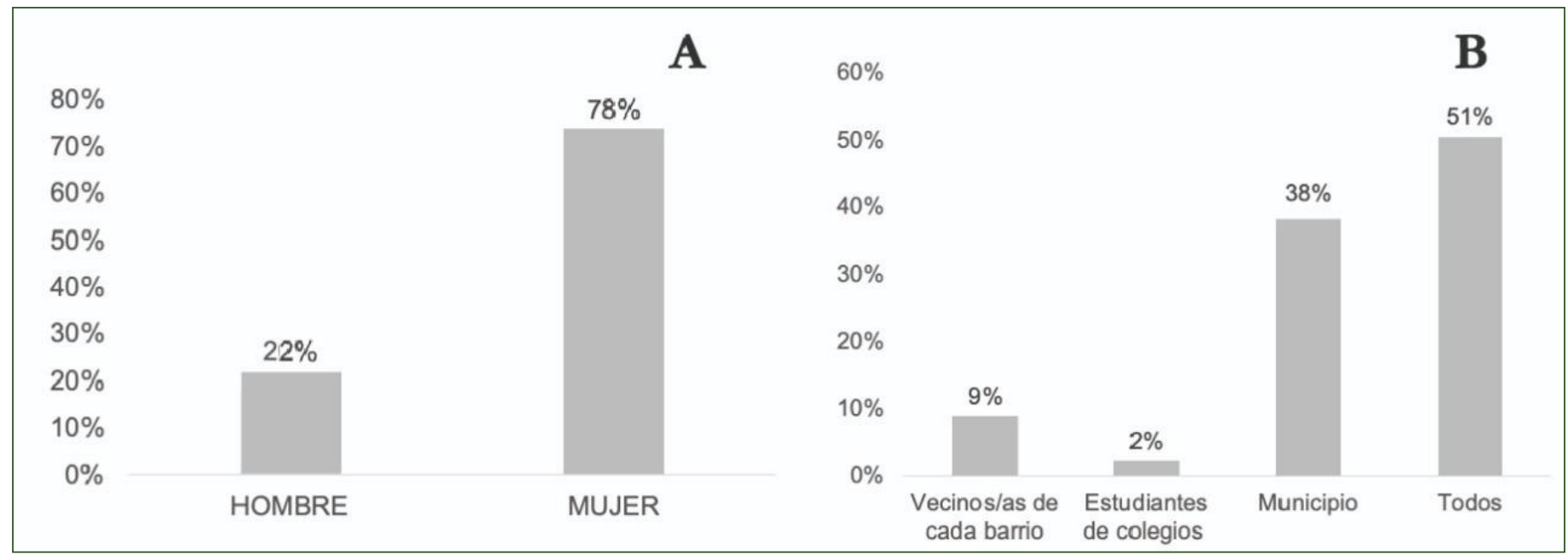

El $78 \%$ de los moradores afirman que las mujeres de la cooperativa se dieron cuenta que la recuperación de la quebrada no solo mejora el paisaje urbano del sector, sino también les permite construir redes vecinales de economía local (Figura 7A). Por otro lado, el 51\% de los miembros de la cooperativa afirman que los alimentos cosechados de los huertos urbanos dentro de la Quebrada Ortega, se convierten en productos de autoconsumo y los excedentes pueden ser comercializados bajo las reglas de un mercado justo y cooperativo que beneficien a todo el sector de Quitumbe (Figura 7B). A partir de esta iniciativa, se organizan ferias culturales los fines de semana donde los moradores del sector acceden a comprar productos orgánicos mientras disfrutan de manifestaciones artísticas y gastronómicas (Figura 8A).

Por otro lado, la incorporación de infraestructura comunal como complemento a la recuperación de la Quebrada sirve para afianzar la
Figura 7: (A) Autogestión liderada por mujeres de la Cooperativa Alianza Solidaria. (B) Participación de la comunidad en ferias de comercialización de alimentos. Fuente: Elaboración Propia. 

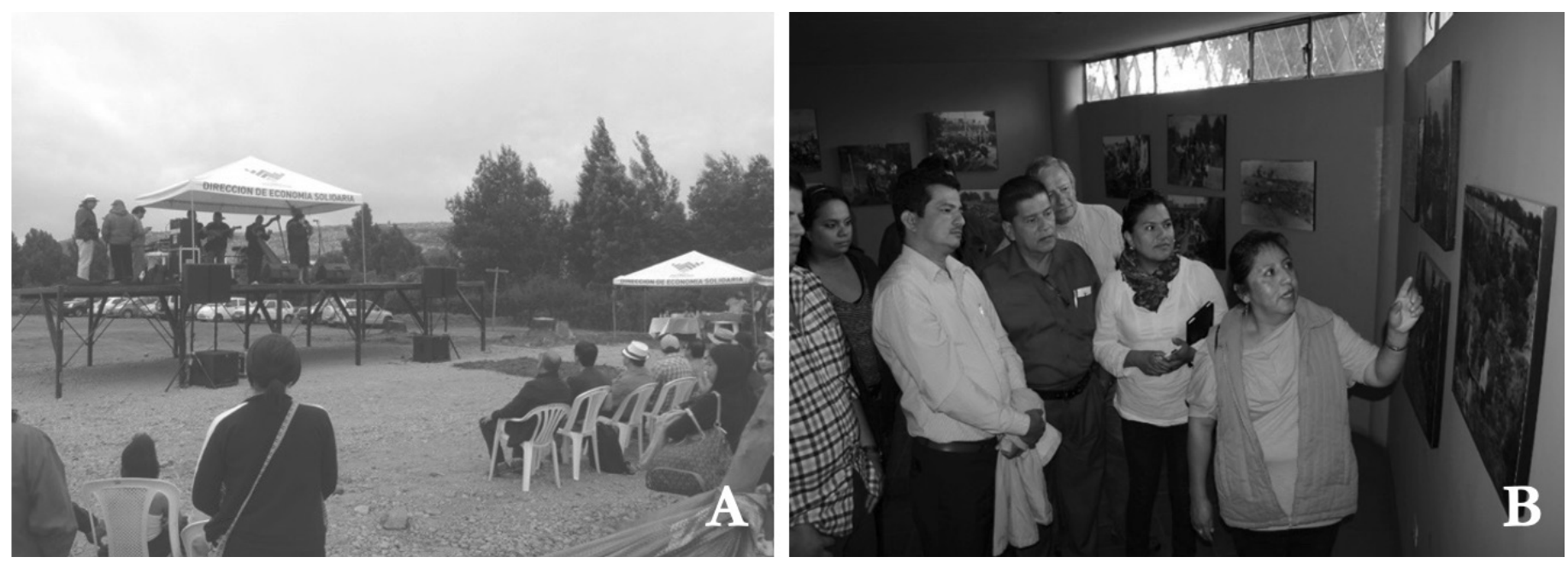

Figura 8: (A) Actividades culturales realizadas por la Cooperativa Alianza Solidaria. (B) Centro de interpretación ambiental. Fuente: COOVIAS (2012). economía local. La Cooperativa Alianza Solidaria construyó el centro de interpretación ambiental donde exponen su experiencia de autogestión en la recuperación de la quebrada a todos los ciudadanos que los visitan y también ofrecen servicios gastronómicos después de cada recorrido por la quebrada (Figura 8B). En este sentido, la autoconstrucción se convierte en una herramienta para fortalecer los procesos de autogestión. En la actualidad, el acompañamiento técnico que brindan varias facultades de arquitectura de la ciudad a la cooperativa, evidencia que la autogestión de esta organización trasciende en diferentes escalas. En este caso, los estudiantes de arquitectura interesados en los procesos de diseño participativo se convierten en el recurso externo a la comunidad que aporta a la producción social del hábitat de la Cooperativa Alianza Solidaria. Sin duda alguna, este caso se convierte en un referente de estudio idóneo para entender una de las formas de ejercer el derecho a la ciudad en la ciudad de Quito.

\section{Mediaciones políticas y Estado}

A partir de las entrevistas a los líderes comunitarios y los resultados de las encuestas a moradores de la cooperativa se identificó la "Mediaciones políticas", como una quinta categoría. En esta investigación, la participación del Estado como organización política que acompaña los procesos de consolidación urbana se reduce a un segundo plano. Primero por la asignación de tierras residuales en la Zona de Quitumbe a un número aproximado de mil familias, segundo por el reconocimiento a las acciones colectivas de la Cooperativa de Vivienda Alianza Solidaria después que terminó el proceso de transformación del territorio y finalmente por la falta de atención a las quebradas en la ciudad después de crear una política pública para su protección.

En este sentido, el 78\% de los moradores afirma que no hace falta la presencia del Estado para vivir de manera digna. Los líderes manifiestan que el sistema hegemónico no considera a los más pobres como actores indispensables para el proceso de urbanización (Figura 9). Pese a que la asignación de tierras fue realizada de manera convencional, es decir, con la aprobación del Estado, la inversión pública no cubre las necesidades básicas de la comunidad. 


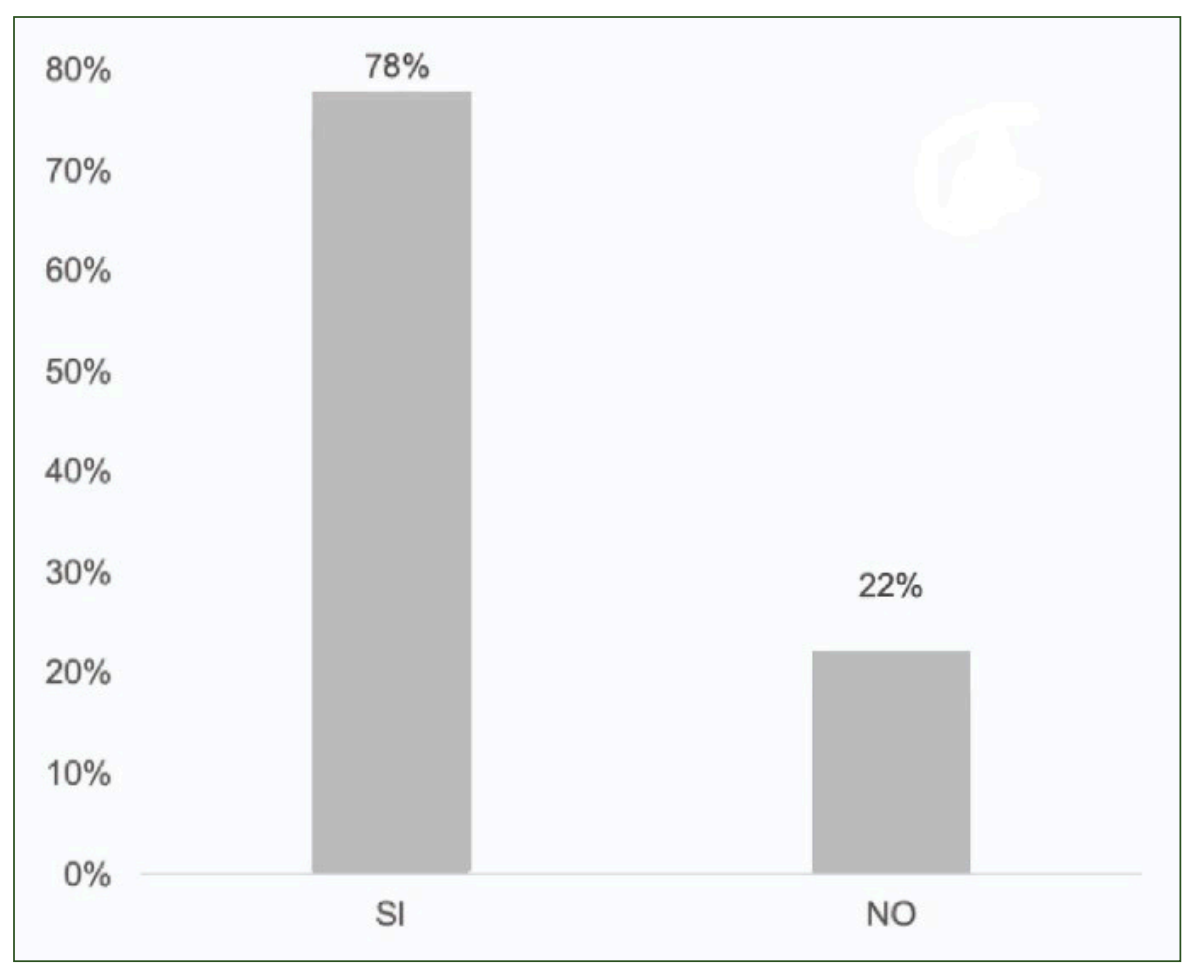

El impacto producido por esta organización social llama la atención a las autoridades como oportunidad para su promoción política. Después de la recuperación de la quebrada, el Estado inició un proceso de mediación donde ofrecieron construir vías, legalizar viviendas y abastecer de servicios básicos la zona (Entrevista a Dirigente-Cooperativa Vivienda Alianza Solidaria, 2016). Por otro lado, también otorgaron reconocimientos ambientales y se creó una política pública donde las Quebradas de Quito se catalogan como espacios públicos patrimonio natural de la ciudad (Consejo Metropolitano de Quito, 2012).

En este contexto, la necesidad de mediaciones entre organizaciones sociales y autoridades es indispensable para preservar y valorar las acciones colectivas en la producción social del espacio público. Sin embargo, los líderes afirman que, a pesar del intento de mediaciones con las autoridades, solamente consiguieron soluciones mediáticas que ponen en riesgo el trabajo realizado por la cooperativa. En este caso, a pesar de que las autoridades reconocen el proceso de la recuperación de la Quebrada Ortega en el ámbito público, la lógica del Estado siempre da prioridad a la construcción de centros comerciales, espacios recreativos privatizados y viviendas masivas. A partir de esta realidad, los líderes afirman que las autoridades deben dar jurisdicción a las organizaciones sociales para continuar con el proceso de producción de la ciudad y defensa de la vida (Entrevista a Dirigente-Cooperativa de Vivienda Alianza Solidaria, 2016).

\section{Discusión}

Las acciones colectivas surgen como una alternativa para construir ciudad especialmente para los individuos que viven en condiciones de pobreza como es el caso de las personas que conforman la Cooperativa Alianza Solidaria en el sur de Quito, donde el acceso a la vivienda y al espacio público se convierte en un privilegio más, no en un derecho (Hernández y Alcántara, 2017). Bajo esta característica también
Figura 9: Percepción de los moradores de la Cooperativa Alianza Solidaria frente al protagonismo del Estado. Fuente: Elaboración Propia. 
existen experiencias que presentan las organizaciones vecinales de la ciudad de La Plata en Argentina, donde los desastres naturales, como inundaciones y la baja de suministro eléctrico en los barrios populares de Los Hornos y San Carlos, se convierten en una oportunidad para generar acciones colectivas, con el objetivo de revertir estos inconvenientes y proponer nuevas actividades que mejoren su calidad de vida (Ursino, Rojas y Muiños, 2020). Esta condición de inequidad social se extiende en la mayoría de ciudades de América Latina, especialmente en los sectores periféricos, donde la falta de infraestructura y escasez de bienes y servicios marcan las condiciones de vida de la población. Es así como las organizaciones sociales, vecinales, cooperativas juegan un papel importante al momento de superar inconvenientes y luchar por alcanzar objetivos en común.

En este contexto para Borja (2011), el espacio público es el escenario donde las organizaciones sociales se hacen visibles, ya que es el medio donde los ciudadanos se expresan libremente y se sienten como iguales. Además, el espacio público debe ser de uso colectivo donde se construya la memoria social que respete la diversidad de identidades de una manera democrática. Esta investigación sugiere que el espacio público también puede ser concebido a partir de una dimensión ambiental donde los recursos naturales, especialmente los productos agrícolas, se conviertan en la base de una economía local, justa y equitativa. En este sentido, las organizaciones sociales imponen resistencia a las prácticas capitalistas donde los espacios verdes son privatizados, como es el caso del Complejo Deportivo Fundeporte en el sur de Quito o el Club Tequendama en la ciudad de Cali, donde grupos de poder sociopolítico adquieren grandes extensiones de zonas verdes de bien público, mediante cambios de uso de suelo generados por las autoridades de turno, con el objetivo de construir complejos recreacionales de acceso restringido para socios o personas que puedan pagar por el uso de la infraestructura (Narváez Muelas, 2019).

Sin duda alguna, se puede afirmar que las acciones colectivas guiadas bajo la lógica de resistencia se convierten en una herramienta social para producir un espacio público donde se mitigue las formas históricas de dominación ideológica (Melucci, 1999; Rodríguez y Zapata, 2020).

Por otro lado, la participación de varios actores se convierte en una acción colectiva indispensable para llevar a cabo la recuperación de la Quebrada Ortega. Aunque autores como Gascon et al. (2010), afirman que las organizaciones sociales funcionan bajo dinámicas implementadas por líderes sociales, los resultados de esta investigación demuestran que la participación activa de diferentes miembros de la comunidad como hombres, mujeres, niños y niñas, permiten producir espacios públicos flexibles y multifuncionales que se adapten a la necesidad de cada uno de los miembros que forman parte de la organización. Aquí es donde las asambleas juegan un papel clave para evaluar, cuestionar, corregir y transmitir el conocimiento adquirido entre todos los participantes, permitiendo que el espacio público sea considerado como un bien común. Retomando el caso de las organizaciones vecinales de la ciudad de la Plata en Argentina, la asamblea también permite el fortalecimiento de las relaciones sociales ya que cada miembro, al expresar cuáles son sus necesidades, problemas y anhelos de una forma cotidiana, cultivan valores como la confianza y el apoyo mutuo. Tanto los vecinos de los barrios de Los Hornos y San Carlos de La Plata y los miembros de la Cooperativa de Vivienda Alianza Solidaria de Quito afirman 
que las asambleas mitigan el aislamiento social y la sensación de inseguridad dentro del barrio y espacio público.

Otro resultado relevante de esta investigación sugiere que las acciones colectivas, emprendidas por la Cooperativa de Vivienda Alianza Solidaria en la recuperación de la Quebrada Ortega, se convierten en una práctica cotidiana que se ejecuta continuamente desde hace aproximadamente treinta años desde su creación. La Quebrada Ortega al ser un recurso natural debe ser protegido y cuidado, es así como los miembros de la cooperativa ejecutan mingas permanentes donde se realizan actividades como reforestación, limpieza, mantenimiento de jardineras y huertos, actividades agrícolas, riego. Esto reafirma la apropiación que sienten los miembros de la cooperativa por este espacio verde público y al mismo tiempo se valora la quebrada como un recurso ambiental que sustenta económica y socialmente su comunidad. Por otro lado, también les permite generar actividades paralelas como ferias gastronómicas, intercambio y venta de alimentos orgánicos, talleres de buenas prácticas ambientales, manifestaciones artísticas y culturales que trascienden generacionalmente dentro y fuera de las familias de la cooperativa. Lo cual se contrapone rotundamente a la afirmación que realiza Garcés (2012), donde las acciones colectivas una vez que se ejecutan tienden a desaparecer.

En este sentido, la autogestión se convierte en una acción colectiva que representa la existencia y permanencia de la Cooperativa de Vivienda Alianza Solidaria. Los resultados de la investigación afirman que para que esta acción se ejecute, todos los miembros de la cooperativa deben participar en la toma de decisiones para alcanzar su objetivo. Por otro lado, también es necesario que la cooperativa cuente con recursos propios sean estos económicos, ambientales, mano de obra, lo cual permite que la acción se desarrolle de forma rápida y eficiente sin depender de ningún actor externo, ya que puede imponer restricciones que beneficien intereses ajenos a la comunidad. En este proceso es necesario destacar el papel de las mujeres al planificar estrategias para la autogestión de redes de economía local; sus conocimientos en las actividades agrícolas permitieron aprovechar los recursos naturales de la Quebrada Ortega y generar redes de economía popular que apoyen la subsistencia de la comunidad. Otro caso que muestra el protagonismo de las mujeres en liderar procesos de autogestión se desarrolla en torno a la construcción del Condominio Habitacional Corazón de María en el cantón de Moravia, Costa Rica donde cuarenta y siete familias guiadas por trece lideresas jefas de hogar, organizan acciones colectivas en busca de acceder a una vivienda propia (Silva Emanuelli, 2018). Las acciones consisten en contratar con sus ahorros una empresa privada de arquitectos para que ejecuten el diseño y construcción del condominio, con el compromiso de que la comunidad participe como mano de obra para abaratar los costos y asegurar la culminación del proyecto. En este proceso hombres y mujeres reciben asesoramiento técnico de la empresa para construir sus viviendas y se convierten en el recurso principal que autogestiona el proyecto. Finalmente, como estímulo al trabajo realizado por esta organización la Fundación Promotora de Vivienda (FUPROVI) con apoyo del Centro Cooperativo Sueco, aportan con recursos donados para la construcción del parque infantil, las zonas de siembra y el portón del condominio. En este contexto, las dos experiencias de autogestión tanto de la Cooperativa de Vivienda Alianza Solidaria y la organización vecinal del Condominio Habitacional Corazón de María, demuestran la capacidad organizativa que tie- 
nen las mujeres en el desarrollo de acciones colectivas en beneficio de la comunidad. Medina (2007) afirma que las acciones colectivas guiadas por mujeres son impulsadas por la sensibilidad social, el bienestar colectivo, el afecto por los miembros de la familia, en especial por sus hijos, y por el deber de cumplir su rol de ciudadanas.

Por otro lado, estas dos experiencias también demuestran la capacidad que tienen las mujeres de generar estrategias para adaptarse a la realidad que vive cada una de las organizaciones, especialmente en el caso del Condominio Habitacional Corazón de María, donde el trabajo de albañilería no se convierte en un impedimento para que las mujeres construyan sus viviendas y produzcan el espacio público. Si bien estas dos organizaciones son reconocidas por su trabajo de acciones colectivas a nivel local e internacional, el apoyo de las autoridades estatales es nulo. En el caso del Condominio Habitacional Corazón de María existen agentes externos no gubernamentales que incentivan su proceso, los mismos que al brindar recursos económicos y materiales demuestran que están alineados con la experiencia y objetivos de esta organización vecinal en Costa Rica. Sin embargo, en el caso de la Cooperativa Alianza Solidaria la asignación de recursos, jurisdicción y competencia que plantean las organizaciones sociales, son reducidas a reconocimientos públicos mediáticos para calmar la resistencia (Abramo, 2013). Finalmente, en esta investigación se demuestra que las políticas públicas creadas con base en las vivencias de las organizaciones sociales no son priorizadas al momento de planificar el territorio lo que permite fortalecer la práctica de las acciones colectivas como un mecanismo para cubrir las necesidades de habitar de las personas más vulnerables.

\section{Reflexiones Finales}

Las acciones colectivas como una herramienta para producir el espacio público se convierten en una práctica cotidiana de la comunidad, donde los individuos incentivados por la necesidad de acceso al suelo y vivienda digna son conscientes de todos los elementos del paisaje urbano y los transforman en recursos que aportan a construir un hábitat donde interactúan con respeto la comunidad y la naturaleza. En este sentido, las acciones colectivas, como por ejemplo la resistencia, el rescate y valoración ambiental, la participación, la autogestión y las mediaciones entre actores, se convierten en las herramientas que construyen una ciudad equitativa en contraposición a las formas tradicionales de planificación territorial adoptada por las autoridades y algunos arquitectos y urbanistas que manejan la ciudad desde una postura que privilegia al mercado.

En esta línea se resalta la autogestión como una acción colectiva que dinamiza la producción del espacio público, ya que la comunidad no tiene que esperar asignación de recursos (económicos, maquinaria, materia prima) para organizarse y emprender su objetivo, esto genera un abanico de oportunidades para que las relaciones sociales se fortalezcan y trasciendan más allá del encuentro mediático como por ejemplo redes permanentes de economía local, grupos de arte y manifestaciones culturales, mingas de mantenimiento del espacio público las mismas que son iniciativa de la comunidad.

Las acciones colectivas emprendidas por la Cooperativa Alianza Solidaria involucran a varios actores como niños y niñas, hombres y mu- 
jeres, personas de la tercera edad con un fin común producir hábitat social, lo que provoca que el espacio público sea concebido como un bien común y que las personas se apropien de la quebrada convirtiéndola en un hito del sector sur de la ciudad de Quito. En este sentido, la participación se convierte en una acción colectiva que representa su identidad y que es transmitida generacionalmente a todos los miembros de las familias que forman parte de la cooperativa. Las acciones colectivas han sido ejecutadas ininterrumpidamente por aproximadamente treinta años, lo cual se contrapone a la afirmación de que los movimientos u organizaciones sociales se disuelven al momento de conseguir su objetivo

Por otro lado, la Cooperativa Alianza Solidaria cambia la concepción que tienen los ciudadanos de las quebradas en la ciudad de Quito (zonas residuales y focos de contaminación) convirtiéndose en espacios verdes públicos que tejen la estructura urbana y dotan de beneficios ambientales a las personas que habitan cerca de estas como por ejemplo productos alimenticios para el consumo y comercialización, altos niveles de satisfacción psicológica al estar en contacto con la naturaleza, bajos niveles de contaminación ambiental, bajo riesgo de inundaciones para sus viviendas.

En esta línea las mujeres juegan un rol muy importante para concebir el espacio público como un recurso que permite autogestionar redes vecinales de economía local en base a productos orgánicos de los huertos construidos en la Quebrada Ortega. Su experiencia en actividades agrícolas adquiridas desde su infancia en el campo permiten instaurar esta práctica como una acción colectiva cotidiana en los miembros de la cooperativa, generando ferias gastronómicas, venta de productos alimenticios y ornamentales, actividades de siembra y cosecha de alimentos lo cual permite que la cooperativa tenga ingresos económicos individuales y colectivos para financiar permanentemente sus acciones y objetivos sin la necesidad de esperar por la asignación de fondos estatales.

Finalmente, la experiencia de la Cooperativa Alianza Solidaria en la recuperación de la Quebrada Ortega incentiva a las autoridades a expedir en el año 2012 la Ordenanza Municipal No 350, donde se declara patrimonio natural, histórico, cultural y paisajístico al sistema de quebradas del Distrito Metropolitano de Quito. Sin duda esta experiencia abre las puertas a futuras profundizaciones sobre el tema que permite reflexionar en la búsqueda de nuevas políticas urbanas, que garanticen el protagonismo de las acciones colectivas en la producción social del espacio público. 


\section{Referencias bibliográficas}

Abramo, Pedro (2013). Mercado informal y producción del hábitat: la nueva puerta de acceso a los asentamientos populares en América Latina. En Bolívar, Teolinda y Erazo Espinosa, Jaime (Eds.), Los Lugares del Hábitat y la inclusión (pp. 29-58). Quito: FLACSO-Ecuador.

Anduze, Víctor (2019). La participación y la apropiación del espacio público como fundamentos del derecho a la ciudad: dos estudios de caso al sur de Mérida, Yucatán. Península, 14(1), 29-50. Recuperado el 01 de julio de 2021 de: http:/ /www.scielo. org.mx/scielo.php?script=sci_arttext\&pid=S1870$57662019000100029 \& \operatorname{lng}=$ es\&tlng $=$ es.

Bermúdez, Nury, Cabrera, Santiago, Carrión, Andrea, Del Hierro, Santiago, Julio, Echeverría, Godard, Henry y Moscoso, Raúl (2016). La investigación urbana en Ecuador (1990-2015): cambios y continuidades. En Metzger, Pascale et. al (Eds.), La cuestión urbana en la región andina. Moradas sobre la investigación y la formación (pp. 117-174). Ecuador: PUCE.

Borja, Jordi (2011). Espacio Público y derecho a la ciudad. Viento Sur, 116, 39-49. Recuperado el 01 de julio de 2021: de https:/ / cdn.vientosur.info/VScompletos/VS116_Borja_EspacioPublico.pdf.

Carrión, Fernando y Erazo, Jaime (2012). La forma urbana de Quito: una historia de centros y periferias. Bulletin de l'Institut français d'études andines, 41(3), 503-522. DOI: https://doi.org/10.4000/bifea.361.

Ceballos, Zeneida y Tovar, Sonia (2010). Autogestión con Jóvenes Rurales: Un camino para el desarrollo social comunitario. Revista Investigium IRE, 1(1), 134-147. Recuperado el 1 de julio de 2021 de: https://investigiumire.unicesmag.edu.co/index. php/ire/article/view/12.

Colding, Johan y Barthel, Stephan (2013). The potential of "Urban Green Commons" in the resilience building of cities. Ecological Economics, 86, 156-166. DOI: http:/ /dx.doi.org/10.1016/j.ecolecon.2012.10.016.

Consejo Metropolitano de Quito (2012). Resolución 350. Declaratoria de patrimonio natural, histórico, cultural y paisajístico al sistema de quebradas del Distrito Metropolitano de Quito.

COOVIAS- Cooperativa de Vivienda Alianza Solidaria (2012). Revista ALPALLACTA, una comunidad autogestionaria para el buen vivir. Quito-Ecuador.

Creswell, John (2013). Qualitative Inquiry and Research Design: Choosing Among Five Approaches. Washington DC: Sage (3. ${ }^{a}$ edición).

Da Ros, Giuseppina (2007). El movimiento cooperativo en el Ecuador. Visión histórica, situación actual y perspectivas. CIRIEC-España, Revista de Economía Pública, Social y Cooperativa, 57, 249-284. Recuperado el 1 de julio de 2021 de https:/ / www.redalyc.org/ articulo.oa?id=17405710.

Delgado, Manuel (2007). Sociedades movedizas. Pasos hacia una antropología de las calles. Barcelona: Anagrama.

Echevarría, Hugo (2019). Métodos de investigación e inferencias en Ciencias Sociales: Una propuesta para analizar su validez. Argentina: UniRío Editora-Universidad Nacional de Río Cuarto.

Espín, María (2012). Los indígenas y el espacio citadino, los lugares de vivienda, en Eduardo Kingman, San Roque: indigenas urbanos, seguridad y patrimonio. Quito: Flacso-Ecuador/Heifer International.

Fernández-Droguett, Roberto (2017). La producción social del espacio público en manifestaciones conmemorativas, Santiago de Chile, 1990-2010. EURE, 43(130), 97-114. DOI: http://dx.doi.org/10.4067/ s0250-71612017000300097.

Forni, Pablo y Grande, Pablo (2020). Triangulación y métodos mixtos en las ciencias sociales contemporáneas. Revista mexicana de sociología, 82(1), 159-189. DOI: https://doi.org/10.22201/ iis.01882503p.2020.1.58064.

Foster, Sheila (2013). City as an ecological space: Social capital and urban land use. Notre Dame Law Review, 82(2), 527-582. Recuperado el 01 de julio de 2021 de: https:/ / scholarship.law.nd.edu/ndlr/ vol82/iss $2 / 1$.

Fry, Mariana (2020). Los movimientos sociales latinoamericanos Teorías críticas y debates sobre la formación. Revista de Ciencias Sociales, 33(47), 13-30. DOI: http://dx.doi.org/10.26489/rvs.v33i47.1.

Garcés, Mario (2012). El despertar de la sociedad. Los movimientos sociales en América Latina y Chile. Santiago. Revista Austral de Ciencias Sociales, 26, 151154. DOI:10.4206/rev.austral.cienc.soc.2014.n26-10.

Gascon, Jordi, Montagut, Xavier, Altieri, Miguel y Bretón, Víctor (2010). ¿Cambio de rumbo en las políticas agrarias latinoamericanas? Estado, movimientos sociales campesinos y soberanía alimentaria. Barcelona: Icaria Editorial.

George, Alexander y Bennett, Andrew (2005). Phase two: Carrying out the case studies. En George, Alexander y Bennett, Andrew, Case Studies and Theory Development in the Social Sciences (pp. 89-108). Cambridge: Belfer Center for Science and International Affairs John F. Kennedy School of Government.

Gierhake, Klaus y Jardon, Carlos (2015). Espacio público en Quito (Ecuador). Un instrumento innovador para implementar el desarrollo territorial. Visión del futuro, 20(1), 44-66. Recuperado el 1 de 
julio de 2021 de: https:/ /visiondefuturo.fce.unam. edu.ar/index.php/visiondefuturo/article/view/54.

Gomá, Ricard y Blanco, Ismael (2003). Gobiernos locales y redes participativas. Barcelona: Editorial Ariel.

González-Díaz, Romel y Serrano, Edgar (2020). Entrevistas Espontáneas Categoriales (EEC) para la construcción de categorías orientadoras en la investigación cualitativa. Journal of Latin American Science, número 2(1), 1-11. Recuperado el 1 de julio de 2020 de: https://lasjournal.com/index.php/abstract/article/view/2.

Grinnell, Richard y Unrau, Yvonne (2005). Social Work Research and Evaluation: Quantitative and Qualitative Approaches. The British Journal of Social Work, 35, 550-551. DOI: https://doi.org/10.1093/ bjsw/bch287.

Guadarrama, Gloria y Pichardo, Pamela (2021). La apropiación y el uso del espacio público urbano. Los comunes en el parque urbano. Economía, sociedad y territorio, 21(65), 57-85. DOI: https://doi. org/10.22136/est2021167857-85.

Harvey, David (2012). Ciudades rebeldes. Del derecho de la ciudad a la revolución urbana. Salamanca: Ediciones Akal.

Hernández, María del Carmen y Alcántara, Nehiby (2017). Construcción de ciudadanía en organizaciones sociales: propuesta de un marco analítico. Sociológica, 32(92), 99-139. Recuperado el 1 de julio de 2021 de: http:/ /www.scielo.org. $\mathrm{mx} /$ scielo.php?script=sci_arttext\&pid=S018701732017000300099\&lng=es\&tlng=es.

Hernández, Roberto; Fernández, Carlos y Baptista, Pilar (2006). Metodología de la investigación. México: MCGraw-Hill Interamericana.

Hogenboom, Bárbara, Baud, Michiel y de Castro, Fabio (2012). Gobernanza Ambiental en América Latina: hacia una agenda de investigación integradora. Comentario Internacional, 12, 57-71. Recuperado el 1 de julio de 2021 de: http://hdl.handle. net/10644/3692.

Lefebvre, Henri (2000). La production de l'espace. París: Anthropos (Obra original publicada en 1974).

Medina, Venus (2007). El empoderamiento de la mujer y la acción colectiva. Revista Venezolana de Estudios de la Mujer, 12(29), 49-62. Recuperado el 1 de julio de 2020 de: http://ve.scielo.org/scielo. php?pid=S1316-37012007000200005\&script=sci abstract.

Melucci, Alberto (1999). Acción colectiva, vida cotidiana y democracia. México: El Colegio de México.

Mena, Alexandra (2010). Las nuevas centralidades urbanas del distrito metropolitano de Quito. Quito: Cepeige.

Narváez Muelas, Diego Armando (2019). Privatización del espacio público verde en la era neoliberal. El Club Tequendama en Cali, Colombia. Bitácora Urbano Territorial, 29(1), 121. DOI: https://doi. org/10.15446/bitacora.v29n1.69048.

Niglas, Katrin (2010). The multidimensional mo- del of research methodology: An integrated set of continua. En Tashakkori, Abbas y Teddlie, Charles (Eds.), SAGE handbook of mixed methods in social E゚ behavioral research (pp. 215-236). Los Angeles: SAGE Publications. DOI: https://dx.doi. org/10.4135/9781506335193.n9.

Olson, Mancur (1986). Auge y decadencia de las naciones: crecimiento económico, estanflación y rigidez social. La lógica de la acción colectiva. Barcelona: Ariel. Recuperado el 1 de julio de 2021 de: https:/ /ses.unam.mx/ docencia/2018II/OlsonMarcur1985_LaLogicaDeLaAccionColectiva.pdf.

Ospina, Juan Camilo y Clavijo, Jairo (2020). De fosa común a parque verde: memoria de la violencia, repolitización del espacio y urbanismo. Sudamérica: Revista de Ciencias Sociales, 12, 274-298. Recuperado el 01 de julio de 2020 de: https:/ / www.researchgate.net/publication/342623707_De_fosa_comun_a_ parque_verde_memoria_de_la_violencia_repolitizacion_del_espacio_y_urbanismo.

Pérez, María Teresa (2018). Espacio público contemporáneo en la ciudad del Siglo Xxi. ¿Crisis o transformación? ACE: architecture, city and environment, 36, 131-140. DOI: https://doi.org/10.5821/ ace.12.36.5300

Priego, Carlos (2011). Naturaleza y Sociedad. El valor de los espacios verdes urbanos. España: Ministerio de Mario Ambiente y Medio Rural y Marino.

Rodrigo, Patricio y Astorga, Benjamín (2014). La naturalidad como nuevo elemento de análisis para el ordenamiento del territorio. Chile: Veintiún.

Rodríguez, María Carla y Zapata, María Cecilia (2020). Organizaciones sociales y autogestión del hábitat en contextos urbanos neoliberales. Íconos. Revista de Ciencias Sociales, 67, 195-216. DOI: https://doi. org/10.17141/iconos.67.2020.3964.

Sautu, Ruth, Boniolo, Paula, Dalle, Pablo y Elbert, Rodolfo (2005). Manual de metodología. Construcción del marco teórico, formulación de los objetivos y elección de la metodología. Buenos Aires: CLACSO.

Silva Emanuelli, María (2018). Vivienda con rostro de mujer. México D.F.: Coalición Internacional para el Hábitat. Recuperado el 1 de julio de 2021 de: https://hic-al.org/wp-content/uploads/2018/12/ Vivienda-con-Rostro-de-Mujer.pdf.

Strauss, Anselm y Corbin, Juliet (2002). Bases de la investigación cualitativa. Técnicas y procedimientos para desarrollar la teoría fundamentada. Antioquia: Editorial Universidad de Antioquia. Recuperado el 1 de julio de 2021 de: https:/ / diversidadlocal.files. wordpress.com/2012/09/bases-investigacion-cualitativa.pdf.

Todd, Zazie, Nerlich, Brigitte, McKeown, Suzanne y Clarke, David (2004). Mixing Methods in Psychology: The integration of Qualitative and quantitative methods in theory and practice. New York: Psychology Press.

Ursino, Sandra, Rojas Chediac, Juan y Muiños Cirone, Maira (2020). Espacio público y acción co- 
lectiva: análisis de los procesos de disputa por la mejora del hábitat en dos barrios periféricos de la Ciudad de la Plata. Revista de Urbanismo, 43, 96-115. DOI: https://doi.org/10.5354/07175051.2020 .55482 .
Verdejo, María del Mar (2013). La sostenibilidad de los espacios verdes urbanos. Bricojardineria y Paisajismo, 177, 1-13. Recuperado el 1 de julio de 2021 de: http:/ / www.horticom.com/revistasonline/revistas/ qej/pdf/06_13.pdf.

Zumárraga Salgado, Maria Daniela, Pascual Wong, Teresa Elena y Unda Padilla, Mauricio Javier (2021). Acciones colectivas en la recuperación de espacios verdes públicos: Caso Quebrada Ortega, Quitumbe, Quito-Ecuador. Hábitat y Sociedad, 14, 51-70.

<https://doi.org/10.12795/HabitatySociedad.2021.i14.04> 